\title{
Compatibilization of Polyamide-6/Syndiotactic Polystyrene Blends Using Styrene/Glycidyl Methacrylate Copolymers
}

\author{
Bin Chen, ${ }^{\dagger \dagger \dagger}$ Tao TAng, Shengqing Xu, Xuequan Zhang, and Baotong HuAng \\ State Key Laboratory of Polymer Physics and Chemistry, Changchun Institute of Applied Chemistry, \\ Chinese Academy of Sciences, Changchun, Jinlin 130022, People's Republic of China
}

(Received June 24, 2002; Accepted November 19, 2002)

\begin{abstract}
Blends of polyamide-6 (PA6) with syndiotactic polystyrene (sPS) were prepared using a series of styrene/glycidyl methacrylate (SG) copolymers as compatibilizers. These copolymers are miscible with sPS, and the epoxide units in SG are capable of reacting with PA6 end groups. These copolymers thus have the potential to form SGg-PA6 graft copolymers at the PA6/sPS interface during melt processing. This study focuses on the effects of functionality and concentration of the compatibilizer on the morphological, mechanical and crystallization behaviors of the blends. In general, SG copolymers are effective in reducing the sPS domain size and improving the interfacial adhesion. About $5 \mathrm{wt} \%$ glycidyl methacrylate (GMA) is the optimum content in SG copolymer that produces the best compatibilization. Both the strength and modulus of the blend have been improved on addition of the SG copolymers, accompanying a loss in toughness when higher concentration copolymer is added. Incorporation of SG compatibilizers to PA6/sPS blend has little influence on the crystallization behavior of PA6 component but resulted in a steady reduction in intensity of crystallinity peak of sPS and simultaneous crystallization of sPS with PA6 is observed.

KEY WORDS Syndiotactic Polystyrene / Polyamide / Polymer Blend / Reactive Compatibilization / Morphology /
\end{abstract}

Polymer blending is an effective way to improve some deficient performances of many polymers. Polyamides (PA) are an attractive class of engineering polymers due to their excellent strength and stiffness, good processability and chemical resistance. However, poor dimensional stability, low heat deflection temperature and high moisture absorption impose limitation in its end use. Attempts have been made to improve these deficiencies by blending of PA with poly(phenylene oxide) (PPO). ${ }^{1-6}$ However, incorporation of PPO usually caused a reduction in chemical stability resulting from poor solvent resistance of PPO.

Syndiotactic polystyrene (sPS) is a new semicrystalline polymer with a melting temperature of about $270{ }^{\circ} \mathrm{C}$. Its high heat-resistance and modulus of elasticity, excellent resistance to chemicals and relatively fast crystallization rate make sPS a potential engineering thermoplastic. ${ }^{7}$ It has gained increasing academic and industrial interests since its first successful synthesis by Ishihara using a metallocene catalyst. ${ }^{8}$ In spite of these desirable properties, a disadvantage of sPS is its inherent brittleness, the application of which calls for its blending with other polymers. Many blends based on SPS and a thermoplastic or elastomeric polymer appeared in patent literature, ${ }^{9-17}$ though only in a few published papers. ${ }^{18-21}$ Blending of PA6 with sPS is certainly an ideal combination to offer new prod- ucts with balanced properties, whereby the advantage of one component can compensate the deficiencies of the other. However, PA6 and sPS are incompatible, simple blends of these two immiscible polymers would give discrete dispersed phases and weak interfacial adhesion, resulting in poor mechanical properties. Therefore, a compatibilizer is required to enhance the interfacial adhesion between the phases of PA6 and sPS. Generally, an effective compatibilizer reduces the interfacial tension between the two phases and leads to a reduction in the domain size and a finer dispersion of one phase in another. Meanwhile, the compatibilizer increases the interfacial adhesion by coupling the phases together and stabilizes the dispersed phase against coalescence. $^{22}$

Compatibilizers are normally block or graft copolymers, often containing segments either miscible with or chemically identical to the respective components of the blend. Another type is a reactive compatibilizer containing functional groups capable of reacting with one of the constituent component to form graft or block copolymers during melt blending. These in situ formed copolymers tend to stay at the interface, acting as an effective compatibilizer between the two immiscible polymers. For blends containing polyamide, reactive compatibilization is regarded to be a better approach to improve compatibility. ${ }^{1,23-27}$

\footnotetext{
${ }^{\dagger}$ To whom correspondence should be addressed (E-mail: mebchen@ust.hk).

${ }^{\dagger}$ Present Address: Department of Mechanical Engineering, Hong Kong University of Science and Technology, Clear Water Bay, Hong Kong.
} 
Styrene/glycidyl methacrylate (SG) copolymers have been demonstrated to be effective reactive compatibilizers for PA/aPS ${ }^{27}$ and PA/PPO systems. ${ }^{2}$ Research showed that aPS was miscible with $\mathrm{SPS},{ }^{28-31}$ and thus this styrene-containing copolymers should be applicable as a reactive compatibilizer for PA6/sPS blends.

In the present study, SG copolymers with various GMA content are synthesized and employed as reactive compatibilizers for PA6/sPS blends. The effects of GMA content and quantity of SG copolymer on morphology, tensile properties and crystallization behaviors of PA6/sPS blends have been explored.

\section{EXPERIMENTAL}

\section{Materials}

PA6 used in this study is a product of Yueyang Petrochemical Co. (China), $M_{\mathrm{n}}=2.2 \times 10^{4}$. The sPS is Questra F2250 from Dow Chemical Co, $M_{\mathrm{w}}=25 \times$ $10^{4}, M_{\mathrm{n}}=9 \times 10^{4}$ (GPC). The SG copolymers with various GMA contents were prepared by suspension polymerization according to the method described in the literature. ${ }^{32}$ The number following SG represents the weight percent of GMA in the SG copolymers.

\section{Blends Preparation}

PA6 and SG copolymers were first dried in a vacuum oven at $80^{\circ} \mathrm{C}$ for $24 \mathrm{~h}$ before blending. All the PA-6/sPS $=80 / 20(\mathrm{w} / \mathrm{w})$ blends were prepared by melt mixing in a $60 \mathrm{ml}$ batch Plastomill (torque rheometer, TOYOSEKI Co.), at $290^{\circ} \mathrm{C}$ and $60 \mathrm{rpm}$ for $10 \mathrm{~min}$. The weight percentage of the SG copolymer in the blends is based on the total weight of each blend. After mixing, the samples were compression molded into sheets with a Ya Don hydraulic press at $290{ }^{\circ} \mathrm{C}$ and $10 \mathrm{MPa}$ for $5 \mathrm{~min}$ and cooled to room temperature. Tensile and morphologic specimens were cut from the molded sheets.

\section{Morphological Observation}

A Hitachi S-570 microscope was used to observe the morphology of the blends. The cryo-fractured surfaces were made by dipping the mold-compressed samples in liquid $\mathrm{N}_{2}$ for more than $10 \mathrm{~min}$, and then fractured. The samples were then etched with boiled xylene in a Soxhlet extractor for moderate time to dissolve the sPS phase at the surface of the specimens. Both the cryogenically fractured and etched surfaces were coated with gold prior to SEM examination.

\section{Mechanical Properties}

Tensile tests were performed at room temperature using dumbbell specimens $(20 \times 4 \times 1 \mathrm{~mm})$ on an Instron
1121 electronic testing instrument at a cross-head speed of $5 \mathrm{~mm} \mathrm{~min}{ }^{-1}$. The samples were dried in a vacuum oven at $80^{\circ} \mathrm{C}$ for $24 \mathrm{~h}$ before the test. Each tensile value reported is the average of 10 to 12 tests.

\section{Thermal Analysis}

The melting and crystallization behavior of the blend was studied using a PerkinElmer DSC-7 under nitrogen atmosphere. To ensure comparable thermal history, all specimens were first heated to $300^{\circ} \mathrm{C}$ for $5 \mathrm{~min}$, then cooled to $50^{\circ} \mathrm{C}$ and reheated to $300^{\circ} \mathrm{C}$, all at a rate of $10^{\circ} \mathrm{C} \mathrm{min}^{-1}$.

\section{RESULTS AND DISCUSSION}

\section{Morphology of the Blends}

Figure 1 shows SEM micrographs of cryogenically fractured surface of a binary PA6/sPS blend and corresponding ternary blends containing different amounts of SG5 copolymer. The uncompatibilized blend shows the typical characteristics of an immiscible blend. The spherical domains of the dispersed sPS phase are large with a broad size distribution (from $c a$. 1-30 $\mu \mathrm{m}$ ). The interface between the PA6 matrix and the dispersed sPS is smooth and clear. Very poor adhesion between the two phases is evidenced by cavities formed on fracturing the specimen (Figure 1a).

On addition of only $2 \mathrm{wt} \%$ SG5 to the PA6/sPS blend, the size of the dispersed particles decreased dramatically and a finer dispersion is obtained. However, still many spherical cavities are observed, suggesting no very strong interfacial adhesion between the two phases (Figure 1b). When the SG5 content is increased to $5 \mathrm{wt} \%$, most of the sPS particles are fractured, denoting further enhancement of the interfacial adhesion, although no significant reduction in SPS domain size (Figure 1c). By adding $10 \mathrm{wt} \% \mathrm{SG} 5$, the morphology of the blend becomes extremely fine with an indistinguishable interface and it is difficult to identify the sPS particles from the matrix. Fractured surface of nearly all the sPS particles suggests very strong interfacial adhesion between the two phases (Figure 1d). It should be pointed out that not the SG copolymer itself but the formed SG-g-PA6 copolymer on reacting of PA6 end groups at the interface during melt blending functions as the compatibilizer. The formation of PS- $g$-PA copolymer during the blending has been confirmed by IR and rheological methods in many studies. ${ }^{1,2,27}$ Morphological observations of the blends indicate that styreneglycidyl methacrylate can be used as a good interfacial agent for compatibilizing PA6/sPS blends and to promote adhesion between the matrix and the dispersed 

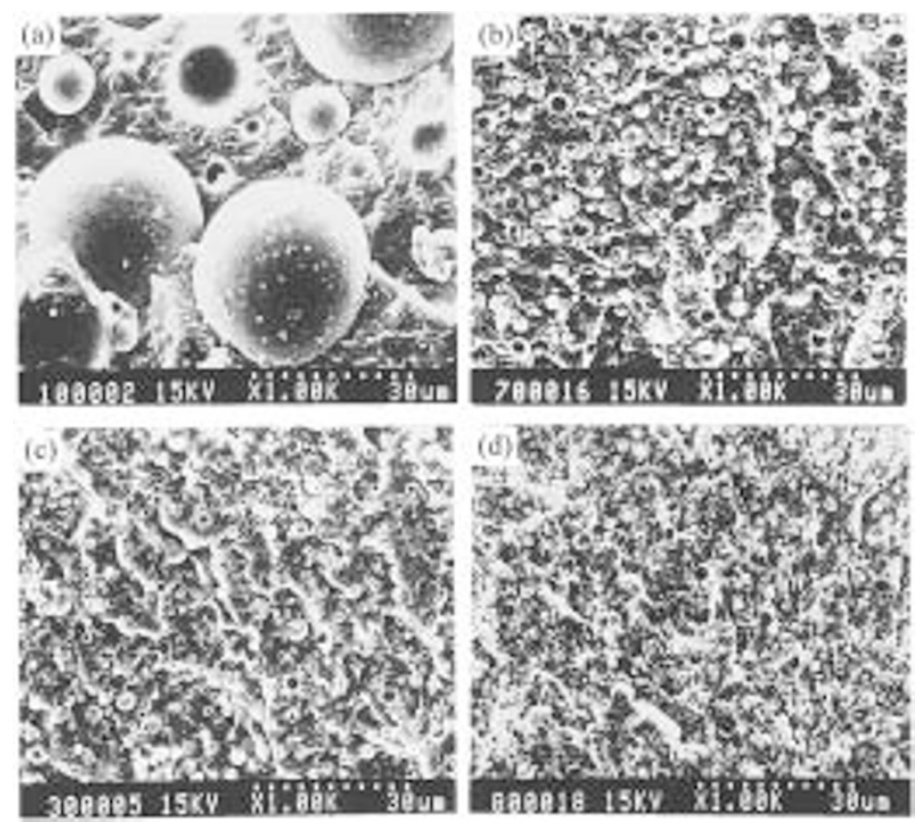

Figure 1. SEM micrographs of fractured surface of PA6/sPS (80/20) blends compatibilized with various amounts of SG5: (a) $0 \mathrm{wt} \%$; (b) $2 \mathrm{wt} \%$; (c) $5 \mathrm{wt} \%$ (d) $10 \mathrm{wt} \%$.
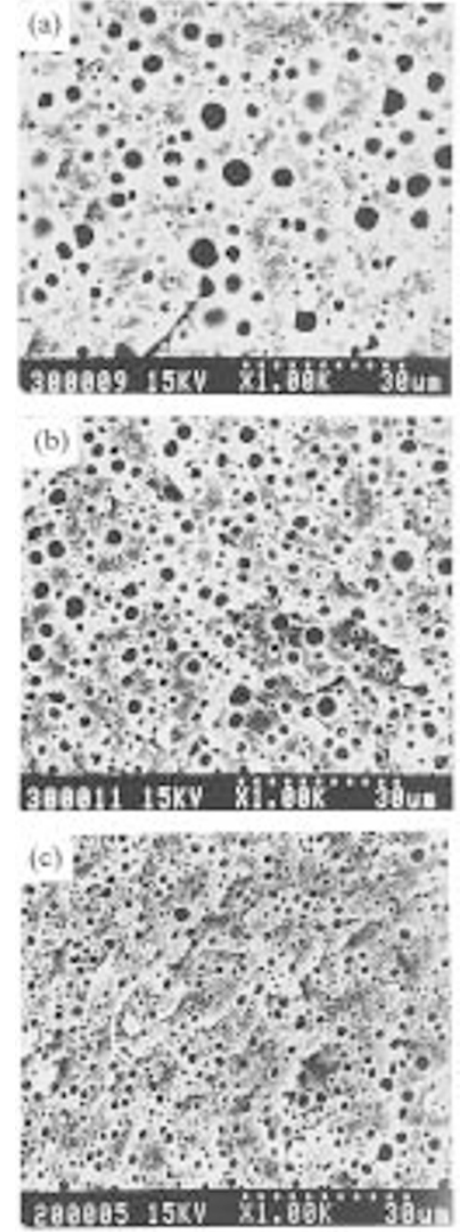

Figure 2. SEM micrographs of the solvent-etched microtomed surfaces of the PA6/sPS (80/20) blends compatibilized with various amounts of SG5: (a) $2 \mathrm{wt} \%$; (b) $5 \mathrm{wt} \%$; (c) $10 \mathrm{wt} \%$.

phase.

Figure $2 \mathrm{a}-2 \mathrm{c}$ show the cryogenically fractured sur- faces of the same set of PA6/sPS blends after solvent etching. The sPS domain sizes change with the concentration of SG copolymer can be clearly identified by these figures.

Effect of GMA content in SG copolymers on the morphology of PA6/sPS blends is presented in Figure 3. It is shown that the lower GMA content compatibilizers (SG1, SG3) result in a stronger interfacial adhesion but a relatively broader domain size distribution. In contrast, the medium GMA content compatibilizer SG5 is effective both in reducing the domain size and in improving the interfacial adhesion. SG10 also appears to be effective in compatibilizing the blend. However, further increase in GMA content (in the case of SG15, SG20) causes negative effect on the blend morphology, as reflected by the smooth surface of sPS particles and the presence of holes, suggesting a very poor interfacial adhesion between the two phases.

Low GMA content SG copolymer tends to form lightly grafted SG-g-PA6 copolymer (one or two grafts per chain). This lightly grafted copolymer has been demonstrated to be the most efficient compatibilizer. ${ }^{1,2}$ However, low GMA content is also expected to form only small amounts of SG- $g$-PA6 copolymer during melt blending; their compatibilizing effect is therefore limited. On the other hand, higher GMA content in SG may produce an excessively grafted comb-like copolymer. Such copolymers have PA6 grafted chains effectively shielding the SG main chain, eventually residing within the PA6 matrix rather than the interface and lose its expected role as an effective compatibilizer. Another reason for the relatively poor compatibilizing effect is 

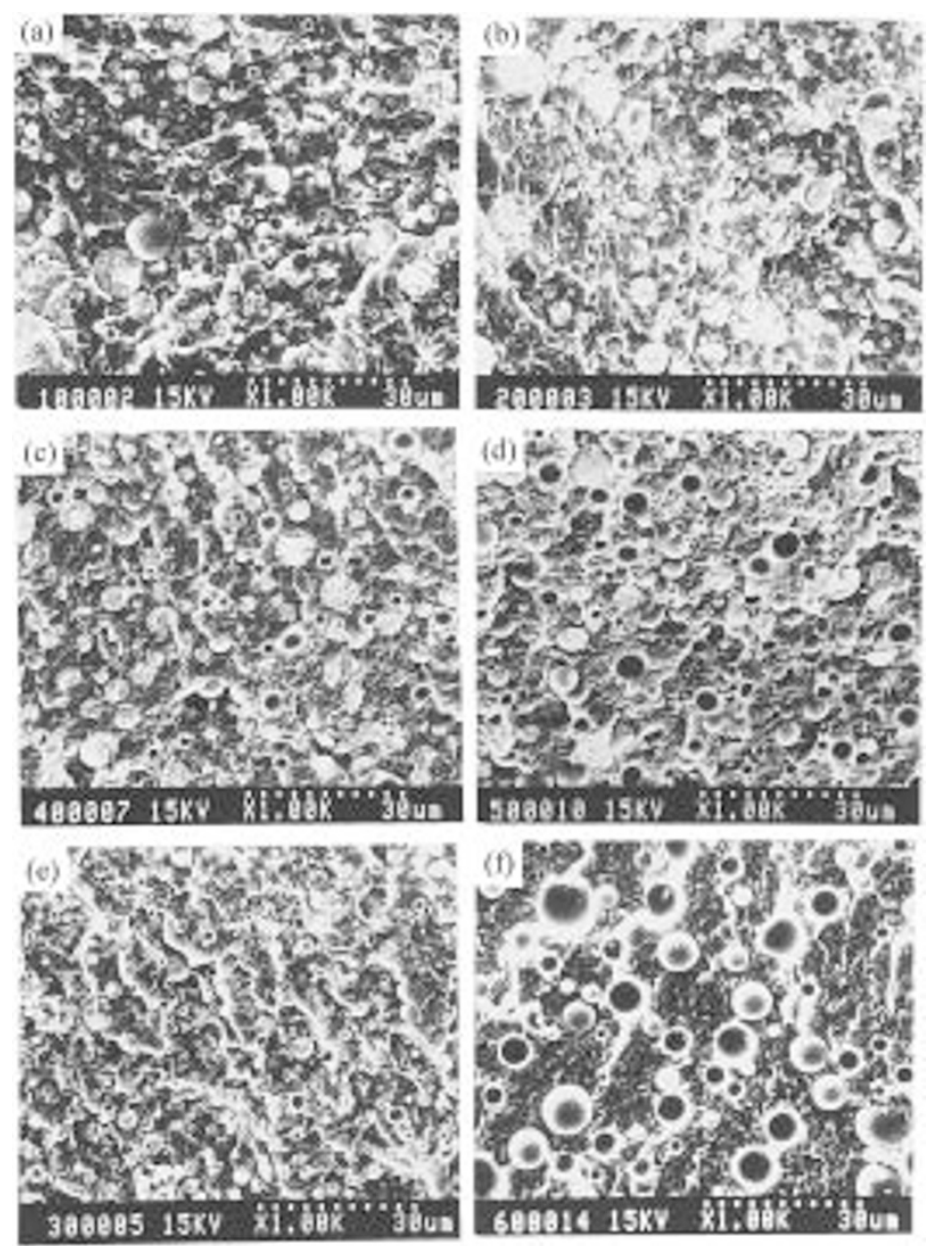

Figure 3. SEM micrographs of fractured surface of PA6/sPS (80/20) blends compatibilized with $5 \mathrm{wt} \%$ of various SG copolymers: (a) SG1; (b) SG3; (c) SG5; (d) SG10; (e) SG15; (f) SG20.

that the SG copolymers with higher GMA content are only partly miscible with sPS. SG5 seems to be the optimum level of GMA content in SG copolymer to compatibilize the PA6/sPS blends.

\section{Mechanical Properties}

The influences of compatibilizer functionality and content on tensile properties of the PA6/sPS blends are summarized in Table I. When GMA content is within $3-10 \mathrm{wt} \%$, the tensile strength is dramatically improved and approaches to that of pure PA6. However, there is only a modest improvement in the tensile strength relative to the binary PA6/sPS blend when GMA content is increased above $15 \mathrm{wt} \%$. Additionally, the tensile strength increases slightly with increase in the quantity of the compatibilizer. The moduli of the compatibilized blends are also higher than that of the uncompatibilized blend, but the extent of the increase is relatively less. The moduli of the blends do not change much with variation of the GMA content in SG copolymers, but increase marginally with increasing quantity of SG copolymers in the blends. The improvement of strength and moduli of the blends can be attributed to both do- main size reduction and increase in interfacial adhesion as shown above.

From Table I, it can also be seen that the value of elongation at break of the unmodified blend is relatively low, owing to the large size of dispersed sPS and very week interfacial adhesion between the two phases. However, addition of SG copolymers to the blends does not cause a remarkably improvement in toughness, even though these SG copolymers are effective in compatibilizing the blends. The toughness of the blends is increased slightly only when the blends contain low concentration SG copolymer and it suffers a reduction when the quantity of the SG copolymers is increased. When the content of SG copolymer is up to $10 \mathrm{wt} \%$, the values of tensile elongation of the blend are even lower than that of the uncompatibilized PA6/sPS blend.

The toughness of polymer blends depends, among other factors, on the morphology and the interfacial properties. Although the reduction of sPS domain size and its finer dispersion caused by compatibilization are advantageous to the improvement in toughness of the blend, the enhanced interfacial adhesion will lower the 
Table I. Tensile properties of PA6/sPS blends (80/20) compatibilized by SG copolymers

\begin{tabular}{|c|c|c|c|}
\hline $\begin{array}{c}\text { Composition } \\
\mathrm{wt} / \mathrm{wt}\end{array}$ & $\begin{array}{c}\text { Tensile properties } \\
(\mathrm{MPa})\end{array}$ & $\begin{array}{c}\text { Tensile elongation } \\
(\%)\end{array}$ & $\begin{array}{l}\text { Young's modulus } \\
\text { (MPa) }\end{array}$ \\
\hline PA6 & 63.5 & 30.0 & - \\
\hline $\mathrm{PA} 6 / \mathrm{sPS}=80 / 20$ & 31.4 & 10.6 & 1015 \\
\hline $\mathrm{PA} 6 / \mathrm{sPS} / \mathrm{SG} 1=80 / 20 / 5$ & 48.3 & 11.2 & 1563 \\
\hline $\mathrm{PA} 6 / \mathrm{sPS} / \mathrm{SG} 3=80 / 20 / 2$ & 51.6 & 13.8 & 1531 \\
\hline $\mathrm{PA} 6 / \mathrm{sPS} / \mathrm{SG} 3=80 / 20 / 5$ & 53.5 & 11.6 & 1587 \\
\hline $\mathrm{PA} 6 / \mathrm{sPS} / \mathrm{SG} 3=80 / 20 / 10$ & 56.8 & 8.9 & 1595 \\
\hline $\mathrm{PA} 6 / \mathrm{sPS} / \mathrm{SG} 5=80 / 20 / 2$ & 53.6 & 14.3 & 1537 \\
\hline $\mathrm{PA} 6 / \mathrm{sPS} / \mathrm{SG} 5=80 / 20 / 5$ & 58.5 & 13.8 & 1582 \\
\hline $\mathrm{PA} 6 / \mathrm{sPS} / \mathrm{SG} 5=80 / 20 / 10$ & 60.4 & 9.2 & 1588 \\
\hline $\mathrm{PA} 6 / \mathrm{sPS} / \mathrm{SG} 10=80 / 20 / 2$ & 52.8 & 14.5 & 1526 \\
\hline $\mathrm{PA} 6 / \mathrm{sPS} / \mathrm{SG} 10=80 / 20 / 5$ & 56.3 & 13.2 & 1558 \\
\hline $\mathrm{PA} 6 / \mathrm{sPS} / \mathrm{SG} 10=80 / 20 / 10$ & 58.4 & 9.6 & 1569 \\
\hline $\mathrm{PA} 6 / \mathrm{sPS} / \mathrm{SG} 15=80 / 20 / 2$ & 46.6 & 14.5 & 1445 \\
\hline $\mathrm{PA} 6 / \mathrm{sPS} / \mathrm{SG} 15=80 / 20 / 5$ & 47.1 & 13.3 & 1496 \\
\hline $\mathrm{PA} 6 / \mathrm{sPS} / \mathrm{SG} 20=80 / 20 / 2$ & 42.2 & 13.8 & 1405 \\
\hline $\mathrm{PA} 6 / \mathrm{sPS} / \mathrm{SG} 20=80 / 20 / 5$ & 44.5 & 12.6 & 1419 \\
\hline
\end{tabular}

elongation. When incorporation of a majority of a brittle polymer into a tough polymer, the increase in the interfacial adhesion usually cause a decrease in toughness of the blend. Similar results have been found in $\mathrm{HDPE} / \mathrm{aPS}^{33}$ and $\mathrm{PP} / \mathrm{sPS}^{34}$ blends. Another important factor that influences the toughness of a blend is the property of SG copolymer itself. After intensive blending, most of SG copolymer will react with PA6 and form SG-g-PA6 graft copolymer. Part of these copolymers will locate at the interface; the excess part will tend to reside in PA6 matrix, especially in the case of formation of highly grafted SG-g-PA6. The brittle SG-g-PA6 copolymers distributed in PA6 matrix will certainly cause the reduction of the toughness of the PA6/sPS blends. This is why the elongation at break of the PA6/sPS blends decrease with the increasing SG content in the blends.

\section{Crystallization Behavior of the Blends}

The DSC crystallization cooling thermograms of PA6/sPS blends compatibilized by SG copolymers with different GMA are shown in Figure 4 with thermograms of virgin PA6 and sPS and incompatibilized blend as references. The crystallization temperature, $T_{\mathrm{c}}$, is $174{ }^{\circ} \mathrm{C}$ for pure PA 6 and $235^{\circ} \mathrm{C}$ for sPS. The $T_{\mathrm{c}}$ of PA6 components in the blends, which is about $188^{\circ} \mathrm{C}$, shifts remarkably to higher temperatures, indicating SPS in the blend can promote the crystallization of PA6 owing to heterogeneous nucleation effect of sPS. Considerable rise in crystallization temperature of the major component in binary blends of semicrystalline polymers, due to the presence of the minor component with higher $T_{\mathrm{c}}$, have been reported in incompatibilized blend systems such as PVDF/PA6, ${ }^{35}$ PVDF/PBTP, ${ }^{35}$ and compatibilized blend systems such as PP/PA6. ${ }^{36}$

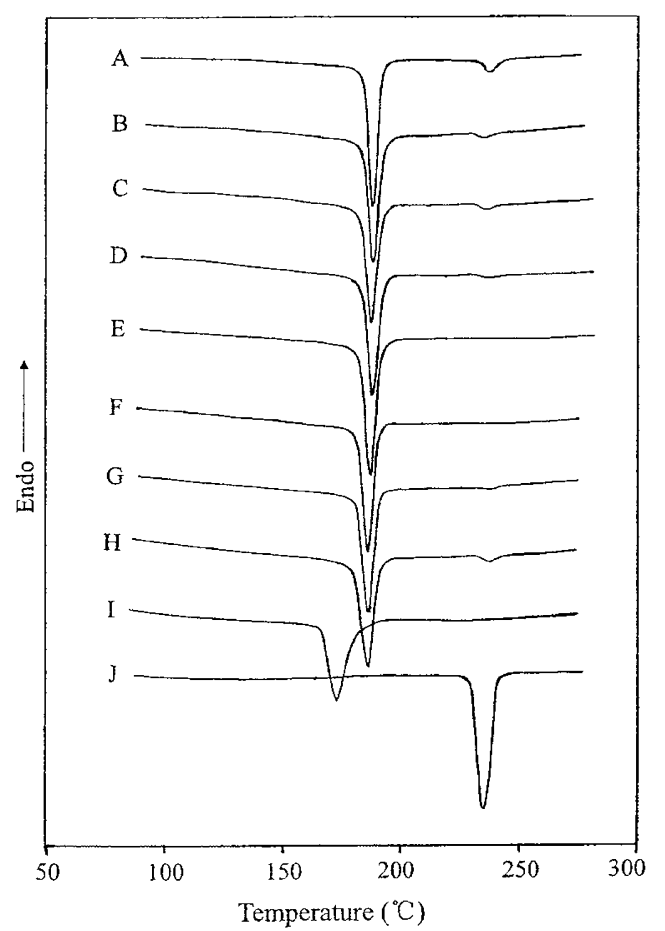

Figure 4. DSC crystallization thermograms of pure sPS, PA6 and PA6/sPS (80/20) blends. Cooling rate: $10^{\circ} \mathrm{C} \mathrm{min}^{-1}$ : (A) $\mathrm{PA} 6 / \mathrm{sPS}=80 / 20 ;$ (B) PA6 $/ \mathrm{sPS} / \mathrm{SG} 1=80 / 20 / 5 ;$ (C) PA6 $/ \mathrm{sPS} / \mathrm{SG} 3=$ 80/20/5; (D) PA6/sPS/SG5 = 80/20/2; (E) PA6/sPS/SG5 = 80/20/5; (F) PA6/sPS/SG5 = 80/20/10; (G) PA6/sPS/SG10 = 80/20/5; (H) PA6/sPS/SG15 = 80/20/5; (I) PA6; (J) sPS.

Variations of GMA content in SG copolymer or quantity of SG copolymers in blends seem to have little influence on the crystallization behaviors of PA6 component in the blends. On the other hand, the crystallization temperature for sPS component, which is at about $235^{\circ} \mathrm{C}$, does not change with addition of SG copolymers. The intensity (magnitude) of the crystallization peaks of the sPS, however, has much to do with the 
GMA content and the quantity of SG in the blends. When GMA content in SG is between $1-3 \mathrm{wt} \%$, addition of $5 \mathrm{wt} \% \mathrm{SG}$ copolymer caused a reduction in intensity of sPS peak. Strikingly, the sPS crystallization peak disappears completely when SG5 is added to the blend. With further increasing in GMA content (10$15 \mathrm{wt} \%$ ), the sPS crystallization peak reappears, but the intensity is still weaker than that of sPS in binary blend. This phenomenon indicates that the crystallization behavior of sPS component depends to a large extent on the morphology of the blends, in particularly, on the sPS domain size and its dispersion. It is suggested that the crystallization of sPS component spilt into two discrete steps: the one crystallize at its usual $T_{\mathrm{c}}$ of $235^{\circ} \mathrm{C}$ and the other at that for PA6. The disappearance of the crystallization peak at usual $T_{\mathrm{c}}$ for SPS implies that nearly the whole SPS component crystallize at $T_{\mathrm{c}}$ for PA6. The crystallization of sPS at $T_{\mathrm{c}}$ for PA6 does not mean that sPS cocrystallized with PA6, as each component exhibits separate melting endotherm (not shown here). Such a phenomenon is called "concurrent crystallization". Similar results have been observed in compatibilized PP/PA6 blends. ${ }^{36-38}$

\section{CONCLUSION}

The effect of GMA content in SG copolymer and quantity of compatibilizer on the behavior of PA6/sPS blends has been investigated. Morphological study shows that the SG copolymers are effective in reducing the sPS domain size and improving the interfacial adhesion in immiscible PA6/sPS blend resulting from the formation of SG-g-PA6 graft copolymer during melt blending. The best compatibilization is achieved for blends containing SG copolymers with medium GMA content (3-5 wt \%), while SG copolymers with lower or higher GMA content display relatively poor compatibilizing effect. When GMA content is within $3-10 \mathrm{wt} \%$, SG copolymers can dramatically improve the tensile strength, while there is only a modestly improvement in the strength of the blend when GMA is below $3 \mathrm{wt} \%$ or above $15 \mathrm{wt} \%$. The modulus of the blend is also improved, which seems to be not influenced by the variation in GMA content. Incorporation of the compatibilizers does not cause a significant increase in toughness of the blend, and at higher SG contents, the break elongation actually becomes somewhat worse than that of the binary PA6/sPS blend. Addition of the compatibilizer to the PA6/sPS blends has little influence on the crystallization behavior of the PA6 component but results in a steady reduction in intensity of the sPS crystallization peak. Incorporation of up to $5 \mathrm{wt} \% \mathrm{SG} 5$ can almost completely suppress the crystallization of sPS at its $T_{\mathrm{c}}$ and induce almost complete concurrent crystallization of sPS and PA6.

Acknowledgments. This research was supported by the National Natural Science Foundation of China. The authors would like to thank Dr. James Tou for his assistance in acquiring the sPS sample from Dow Chemical Co.

\section{REFERENCES}

1. C. R. Chiang and F. C. Chang, Polymer, 38, 4807 (1997).

2. C. R. Chiang and F. C. Chang, J. Appl. Polym. Sci., 61, 2411 (1996).

3. Y. C. Lai, J. Appl. Polym. Sci., 54, 1289 (1994).

4. J. R. Campbell, S. Y. Hobbs, and V. H. Watkins, Polym. Eng. Sci., 30, 1056 (1990).

5. K. Suzuki and S. Ono, Japanese Patent 60-155259 (Aug. 15, 1985).

6. H. Kasahara, K. Fukuda, and H. Suzuki, Japanese Patent, 5736150 (Feb. 26, 1982).

7. R. Po and N. Cardi, Prog. Polym. Sci., 21, 47 (1996).

8. N. Ishihara, T. Seimiya, M. Kuramoto, and M. Uoi, Macromolecules, 19, 2464 (1986).

9. T. Ijits, T. Sumitomo, M. Sawada, and K. Fuaki, Eur. Patent 318793 (July 7, 1988).

10. T. Sumitomo and K. Funaki, Eur. Patent 324389 (July 19, 1989).

11. E. Albizzati, I. Borghi, and G. Giunchi, Eur. Patent 314146 (May 3, 1989).

12. A. Okada and A. Masuyama, Eur. Patent 546497 (June 16, 1993).

13. A. Okada, Eur. Patent 587098 (Mar. 16, 1994).

14. A. Okada and N. Sato, Eur. Patent, 587100 (Mar. 16, 1994).

15. A. Okada, and A. Musuyama, Eur. Patent, 591823 (Apr. 13, 1994).

16. C. C. Chou, U. S. Patent 5241015 (Aug. 31, 1993).

17. A. Okada and S. Machida, U. S. Patent, 5412024 (May 2, 1995).

18. S. Xu, B. Chen T. Tang, and B. Huang, Polymer, 40, 3399 (1999).

19. L. Abis, L. Abbondanza, R. Braglia, L. Castellani, G. Giannotta, and R. Po, Macromol. Chem. Phys., 201, 1732 (2000).

20. B. K. Hong and W. H. Jo, Polymer, 41, 2069 (2000).

21. B. Chen, X. Li, S. Q. Xu, T. Tang, B. L. Zhou, and B. T. Huang, Polymer, 43, 953 (2002).

22. D. R. Paul and S. Newman, Ed., "Polymer Blends vol 2.", Academic Press, Inc., NewYork, N.Y., 1978, Chapt. 12.

23. R. A. Kudva, H. Keskkula, and D. R. Paul, Polymer, 39, 2447 (1998).

24. B. Majumder, H. Keskkula, and D. R. Paul, Polymer, 35, 3164 (1994).

25. I. Park, J. W. Barlow, and D. R. Paul, J. Polym. Sci., Part B: Polym. Phys., 30,1021 (1992).

26. V. J. Triacca, S. Ziaee, J. W. Barlow, H. Keskkula, and D. R. Paul, Polymer, 32, 1401 (1991).

27. F.C. Chang and Y. C. Hwu, Polym. Eng. Sci., 31,1509 (1991).

28. S. Xu, B. Chen, Y. Liu, H. Chen, and B. Huang, Chin. Chem. 
Lett., 9, 407 (1998).

29. H. Ermer, R. Thomann, J. Kressler, R. Brenn, and J. Wunsch, Macromol. Chem. Phys., 198, 3639 (1997)

30. B. K. Hong, W. H. Jo, and J. Kim, Polymer, 39, 3753 (1998).

31. M. Bonnet, M. Buhk, G. Trogner, K. D. Rogausch, and J. Petermann, Acta. Polym., 49, 174 (1998).

32. M. N. Bureau, H. E. L. Kadi, J. Denault, and J. I. Dickson, Polym. Eng. Sci., 37, 377 (1997).

33. M. C. Maa and F. C. Chang, J. Appl. Polym. Sci., 49, 613 (1993).
34. B. Chen, X. L. Li, S. Q. Xu, T. Tang, X. Q. Zhang, and B. T. Huang, Macromol. Chem. Phys., submitted for publication.

35. H. Frensch and B.-J. Jungnickel, Colloid Polym. Sci., 267, 16 (1989).

36. H. S. Moon, B. K. Ryoo, and J. K. Park, J. Polym. Sci., Polym. Phys. Ed., 32, 1427 (1994).

37. O. T. Ikkala, R. M. Holsti-Miettinen, and J. Seppala, J. Appl. Polym. Sci., 49, 1165 (1993).

38. T. Tang, Z. Lei, X. Zhang, H. Chen, and B. Huang, Polymer, 36, 5061 (1995). 